\title{
The overexpression of IncRNA H19 as a diagnostic marker for coronary artery disease
}

\author{
Gang Xiong ${ }^{2}$ \\ D Xuejun /iang ${ }^{1}$ \\ (iD) Tao Song ${ }^{1,3}$
}

\begin{abstract}
1. Department of Cardiology, Renmin Hospital of Wuhan University, Cardiovascular Research Institute of Wuhan University, Hubei Key Laboratory of Cardiology, Jiefang Road 238, Wuchang, 430060, Wuhan, PR China 2. Department of Cardiology, Wuhan Asia Heart Hospital, Wuhan, China 3. Department of Cardiology, the 4th Division Hospital of Xinjiang Production and Construction Corps, Bole, Xinjiang, China.
\end{abstract}

\begin{abstract}
SUMMARY
OBJECTIVE: Our study aimed to investigate the diagnostic value of InCRNA H19 for coronary artery disease (CAD) and to explore its possible mechanisms. Methods: A total of 30 CAD patients and 30 healthy individuals, as well as patients with different cardiovascular diseases, were included in this study. Blood was drawn from each participant to prepare serum samples, and the expression of IncRNA H19 was detected using qRT-PCR. The ROC curve analysis was used to analyze the diagnostic value of H19 for CAD. The effects of patients' basic information and lifestyle on H19 expression were analyzed. The plasma level of TGF- $\beta 1$ was measured by ELISA. The H19 overexpression in the human primary coronary artery endothelial cell (HCAEC) line was constructed, and the effects of H19 overexpression on the TGF- $\beta 1$ expression were analyzed using Western blot. The results of H19 expression were specifically upregulated in patients with CAD but not in healthy individuals and patients with other types of cardiovascular diseases. The ROC curve analysis showed that the H19 expression level could be used to predict CAD accurately. Gender, age, and patients' lifestyle had no significant effects on H19 expression, but H19 expression was higher in patients with a longer course of disease in comparison with the controls. H19 expression was positively correlated with the serum level of TGF- $\beta 1$, and H19 overexpression significantly increased TGF- $\beta 1$ protein level in HCAEC. Conclusion: H19 overexpression participates in the pathogenesis of CAD by increasing the expression level of TGF- $\beta 1$, and $\mathrm{H} 19$ expression level may serve as a diagnostic marker for CAD.
\end{abstract}

KEYWORDS: Coronary artery disease. Diagnosis. RNA, Long Noncoding. Transforming Growth Factor beta1.

\section{INTRODUCTION}

Coronary artery disease (CAD) is the leading type of heart disease, and it develops when major blood vessels responsible for supplying oxygen, blood, and nutrients to the heart become diseased or damaged after the formation of plaques ${ }^{1}$. Despite the high mortality of other severe diseases, such as malignant tumors, CAD is still considered to be a major cause of deaths worldwide ${ }^{2}$. In America, CAD causes one death every 1 minute and is responsible for one-third of all deaths among people older than 35 years ${ }^{1}$. The condition is even worse in China. A recent study has shown that more than $40 \%$ of all deaths in China are caused directly by CAD or its complications ${ }^{3}$. Angioplasty and bypass surgery are the two main methods

DATE OF SUBMISSION: 15-May-2018

DATE OF ACCEPTANCE: 26-May-2018

CORRESPONDING AUTHOR: Xuejun liang

Department of Cardiology, Renmin Hospital of Wuhan University,

Cardiovascular Research Institute of Wuhan University, Hubei Key Laboratory of Cardiology

jiefang Road 238, Wuchang, 430060, Wuhan, PR China

Email: er10oqOc40p51g@163.com

CORRESPONDING AUTHOR: Tao Song

Department of Cardiology, Renmin Hospital of Wuhan University, Cardiovascular

Research Institute of Wuhan University, Hubei Key Laboratory of Cardiology

Jiefang Road 238, Wuchang, 430060, Wuhan, PR China

Department of Cardiology, the 4th Division Hospital of Xinjiang Production and Construction Corps, Bole, Xinjiang, China.

Email: z19kkjw4ctg8s@163.com 
used in the treatment of CAD, but their effects are not lasting 4,5 . As a non-invasive method, drug treatment is still the most widely used treatment for CAD; however, drug tolerance can be developed during long-term treatment, and adverse side effects lead to unsatisfactory treatment outcomes ${ }^{6}$. Therefore early diagnosis and treatment are vital in improving treatment outcomes of CAD.

Serum biomarkers, which are relatively easy to be obtained, have been widely used in the diagnosis of various human diseases ${ }^{7,8}$. Long non-coding RNA (IncRNA) are RNAs without protein-coding ability. LncRNAs contain more than 200 nucleotides, which is significantly longer than miRNA, siRNA and other shorter RNAs ${ }^{9}$. Previous studies have shown that lncRNAs are involved in almost every aspect of key biological or even pathological processes in the human body ${ }^{10}$, and abnormal expression of many lncRNAs in serum has been proved to predict a variety of human diseases accurately. A recent study has shown that IncRNA H19 is significantly correlated with the increased risk of CAD. However, its diagnostic value for CAD and mechanism are still unclear.

In this study, the expression of H19 in the serum of patients with CAD and other types of cardiovascular diseases was detected. The diagnostic value of $\mathrm{H} 19$ for CAD was explored, and the effect of H19 overexpression on TGF- $\beta 1$ was also investigated.

\section{METHODS}

\section{Patients}

A total of 30 patients with CAD and 30 healthy individuals (control group) were selected and enrolled from January 2016 to January 2017 in the Renmin Hospital of the Wuhan University. CAD diagnosis was performed in strict accordance with the diagnostic criteria established by the American College of Cardiology/American Heart Association (AHA). Exclusion criteria: (1) patients with a malignant tumor or other major organ diseases; (2) patients with a serious infection over the 6 weeks before the beginning of this study; (3) patients with active chronic inflammatory disease; (4) patients with mental disease. A total of 30 patients were included (14 females and 16 males) and their age ranged from 25 to 76 years, with an average age of $46 \pm 10.7$ years. The control group included 15 males and 15 females, and the age ranged from 24 to 71 years, with an average age of $47 \pm 9.6$ years. There were 8 cases of hypertension, including 4 males and 4 females ( 22 to 78 years old, with an average age of $49 \pm 14.3$ years); 9 cases of type I diabetes, including 4 males and 5 females (29 to 72 years old, with an average age of $46 \pm 10.1$ years); 10 cases of type II diabetes mellitus, including 5 males and 5 females (31 to 77 years old, with an average age of $48 \pm 9.4$ years); 7 cases of abnormal aoritic aneurysm, including 3 males and 4 females (24 to 79 years old, with an average age of $51 \pm 14.1$ years.); 8 cases of valvular disease, including 4 males and 4 females (33 to 73 years old, with an average age of $51 \pm 12.4$ years); 17 cases of dilated cardiomyopathy, including 8 males and 9 females (31 to 72 years old, with an average age of $45 \pm 17.1$ years); 6 cases of viral myocarditis, including 3 males and 3female (31 to 77 years old, with an average age of $50 \pm 11.4$ years); 10 cases of atrial fibrillation, including 6 males and 3 females (31 to 66 years old, with an average age of $48 \pm 13.2$ years); and 12 cases of peripheral artery disease, including 7 males and 7 females (23 to 61 years old, with an average age of $43 \pm 13.1$ years). There were no significant differences in the background information of patients with different diseases. The Ethics Committee of the Renmin Hospital of the Wuhan University approved this study. All patients signed informed consent.

\section{Blood extraction and serum preparation}

Whole blood $(100 \mathrm{ml})$ was collected from each patient. Blood was kept at room temperature for 2 $\mathrm{h}$, followed by centrifugation at $2500 \mathrm{rpm} / \mathrm{min}$ for 15 min and. The supernatant (serum) was then collected. Serum samples were maintained at $4{ }^{\circ} \mathrm{C}$ before usage.

\section{Cell culture}

Human primary coronary artery endothelial cells (HCAEC) were purchased from ATCC (ATCC ${ }^{\circledR}$ PCS100-020 ${ }^{\mathrm{TM}}$ ) and were cultured in strict accordance with the instructions provided by ATCC. Cells were harvested during the logarithmic growth phase for subsequent experiments.

\section{ELISA to measure the serum level of TGF- $\beta 1$}

The ELISA-Quantikine kit (R\&D Systems, Minneapolis, MN, USA) was used to measure the levels of TGF- $\beta 1$ in serum in strict accordance with the manufacturer's instructions. The detection range for TGF- $\beta 1$ was $100-1200$ ng/L. 


\section{Establishment of IncRNA H19 overexpression} cell lines

The HCAEC cell was cultured overnight to reach $80-90 \%$ confluence. H19 cDNA was inserted into the GV299 lentiviral vector according to the methods described previously. After transfection, the cells were cultured overnight at $37^{\circ} \mathrm{C}$ before collection.

\section{Real-time quantitative reverse transcription} PCR

Total RNA was extracted from the cells and serum using a Trizol reagent (Invitrogen, USA). The RNA samples were tested using a UV spectrophotometer, and only the ones with OD260/OD280 ratio between 1.8 and 2.2 were used in the reverse transcription with SuperScript IV Reverse Transcriptase (Thermo Fisher Scientific, USA) to synthesize cDNA. The PCR reaction system was prepared using SYBR $^{\circledR}$ Green Real-Time PCR Master Mixes (Thermo Fisher Scientific, USA). The following primers were used: 5'- ATCGGTGCCTCAGCGTTCGG-3' (sense) and 5'- CTGTCCTCGCCGTCACACCG-3' (antisense) for IncRNA H19; 5'-CCCAGCATCTGCAAAGCTC-3' (sense) and 5'-GTCAATGTACAGCTGCCGCA-3' (antisense) for TGF- $\beta 1$; 5'-GACCTCTATGCCAACACAGT-3' (sense) and 5'-AGTACTTGCGCTCAGGAGGA-3' (antisense) for $\beta$-actin. CFX96 Touch $^{\mathrm{TM}}$ Real-Time PCR Detection System (Bio-Rad, USA) was used to carry out PCR reaction. Reaction conditions were: $95{ }^{\circ} \mathrm{C}$ for $30 \mathrm{~s}$, followed by 40 cycles of $95{ }^{\circ} \mathrm{C}$ for $10 \mathrm{~s}$ and $65{ }^{\circ} \mathrm{C}$ for $30 \mathrm{~s}$. The $2^{-\Delta \Delta \mathrm{CT}}$ method was used to process $\mathrm{Ct}$ values, and the expression level of each gene was normalized to endogenous control $\beta$-actin.

\section{Western-blot}

Total protein was extracted from cells using cell lysis solutions (Thermo Fisher Scientific, USA) and then it was quantified by BCA assay. $20 \mu \mathrm{g}$ of protein from each sample was subjected to $10 \%$ SDSPAGE electrophoresis, followed by transmembrane to PVDF membrane. After washing, the membranes were blocked with $5 \%$ skimmed milk at room temperature for $1 \mathrm{~h}$, followed by incubation with corresponding primary antibodies, including rabbit anti-TGF- $\beta 1$ antibody (1: 1000 , ab92486, Abcam) and rabbit anti- $\beta$-actin antibody (1: 1000, ab8226, Abcam) overnight at $4{ }^{\circ} \mathrm{C}$. After washing, the anti-rabbit IgG-HRP secondary antibody (1: 1000, MBS435036, MyBioSource) was added and incubated with the membranes at room temperature for $4 \mathrm{~h}$. After washing, signal detection was performed using ECL detection reagent (Sigma-Aldrich, USA). The expression level of TGF- $\beta 1$ was normalized to endogenous control $\beta$-actin using image $\mathrm{J}$ software.

\section{Statistical analysis}

SPSS19.0 (SPSS Inc., USA) software was used. The normal distribution data were recorded $(x \pm \mathrm{s})$, and comparisons between the two groups were performed using the t-test. Comparisons among multiple groups were performed using ANOVA. Non-normal distribution data were analyzed using the non-parametric Mann-Whitney U test. Fisher's exact probability test or chi-square test was used to analyze the correlations between H19 expression and various clinical data. The correlation between the serum level of H19 and TGF- $\beta 1$ was analyzed using Pearson correlation analysis. $\mathrm{P}<0.05$ was considered to be statistically significant.

\section{RESULTS}

The serum level of IncRNA H19 in patients with CAD

QRT-PCR was used to detect the expression of H19 in serum samples of 30 CAD patients and 30 healthy individuals. The results showed that the expression level of H19 was significantly higher in CAD patients than in the control group (Fig. 1A), which indicates that an increased expression level of H19 is very likely to be involved in the pathogenesis of CAD. The diagnostic value of H19 for CAD was analyzed using a ROC curve. As shown in Fig. $1 \mathrm{~B}$, the area under the ROC curve was $0.9367(\mathrm{p}<$ 0.001) with a $95 \%$ confident interval of 0.8797 to 0.9936 , suggesting that $\mathrm{H} 19$ is a promising biomarker for CAD.

Differential expression of IncRNA H19 in patients with different types of cardiovascular diseases

H19 has been proved to be involved in the pathogenesis of various cancers. However, the expression pattern of $\mathrm{H} 19$ in diabetes mellitus, as well as in different types of cardiovascular diseases, still has not been reported. Therefore, in this study, the expression level of $\mathrm{H} 19$ in the serum of patients with CAD, type 1 diabetes, type 2 diabetes and various cardio- 
vascular diseases including hypertension, abnormal aortic aneurysm, valvular disease, dilated cardiomyopathy, viral myocarditis, atrial fibrillation, and peripheral artery disease was detected (Fig. 1C). Compared with control groups and patients with other types of cardiovascular diseases, the expression level of $\mathrm{H} 19$ was explicitly and significantly increased in the serum of patients with CAD $(p<0.05)$. There were no significant differences in the expression level of H19 between the control and patients with other diseases $(p>0.05)$. Using CAD, other heart diseases, gender, age and individual's living habits (smoking, drinking and vegetarian) as independent variables and serum $\mathrm{H} 19$ as a dependent variable, linear regression analyses were performed. The results showed that only CAD was a potential predictor [regression coefficient $(\mathrm{B})=-0.299 ; \mathrm{p}=0.000]$, and other variables provided a p-value higher than 0.05. These results suggest that the increased expression of GAS5 can potentially serve as a specific diagnostic biomarker for CAD.

Correlation between the expression level of $\mathrm{H} 19$ and basic information of CAD patients

Above data have shown that H19 may potentially serve as a diagnostic marker for CAD. However, lncRNA expression can be induced or regulated by patients' living habits, such as smoking and drinking, which in turn affect the diagnostic value. Therefore, the effects of the background and living habits on the expression of H19 in CAD patients were investigated. According to the median expression level of H19, 30 CAD patients were divided into a high expression group and a low expression group, with 15 patients in each. Gender, age, smoking, drinking, and vegetarian diet had no significant effects on H19 expression, while the expression level of H19 was significantly higher in patients with a duration of disease $>5$ years than in patients with a duration of disease $<=5$ years. These data suggest that an increased H19 expression level can accurately diagnose CAD for patients with different backgrounds and lifestyles, especially those with longer duration of disease.

Correlation between serum level of $\mathrm{H} 19$ and serum level of TGF- $\beta 1$

An increased TGF- $\beta 1$ level in the blood has been proved to be closely correlated with the development of CAD. Therefore, the serum level of
TGF- $\beta 1$ in both CAD patients and healthy individuals was detected using ELSIA. As shown in Fig. $2 a$, the serum level of TGF- $\beta 1$ was significantly higher in CAD patients compared with healthy control individuals. Also, the Pearson correlation analysis showed that serum expression level of H19 was positively correlated with the serum level of TGF- $\beta 1$ (R=0.0119, $\mathrm{p}<0.00001)$. These results suggest that $\mathrm{H} 19$ expression is positively correlated with TGF- $\beta 1$ expression.

$\mathrm{H} 19$ overexpression increased the expression level of TGF- $\beta 1$ in HCAECs

Studies have shown that $\mathrm{H} 19$ is related to CAD. While its mechanism is still unknown, it is well known that $\mathrm{H} 19$ can interact with TGF- $\beta 1$, and that TGF- $\beta 1$ is related to the development of CAD. Therefore, the interactions between H19 and TGF- $\beta 1$ were investigated through H19 overexpression. As shown in Fig. 3a, compared with control cells and negative control cells (empty virus vector transfection), the expression of $\mathrm{H} 19$ was significantly increased after the transformation with $\mathrm{H} 19$ expressing vector, indicating the successfully established H19 overexpression cells line. After H19 overexpression, the expression level of TGF- $\beta 1$ was significantly increased at both mRNA level (Fig. 3b) and protein level (Fig. 3c). These data suggest that $\mathrm{H} 19$ can promote the expression of TGF- $\beta 1$ to participate in CAD.

\section{DISCUSSION}

CAD is responsible for more than one-third of all deaths worldwide $[1,3]$. With the development of modern society and the changes in people's diet structure as well as lifestyle, the incidence of obesity, which is an independent risk factor for CAD, has increased dramatically, leading to a significant increase in the incident of CAD. So far, CAD treatment is challenged by poor outcomes as well as adverse effects. Therefore, early diagnosis and treatment may be a promising way to improve treatment outcomes. The development of diseases, such as malignant tumors and inflammatory diseases, is usually accompanied by changes in serum levels of certain substances. Therefore, serum biomarkers, which are relatively easy to be obtained, have been widely used in the diagnosis of various human diseases. In a recent study, Zhang et al. reported that serum omentin-1 levels were significantly reduced 

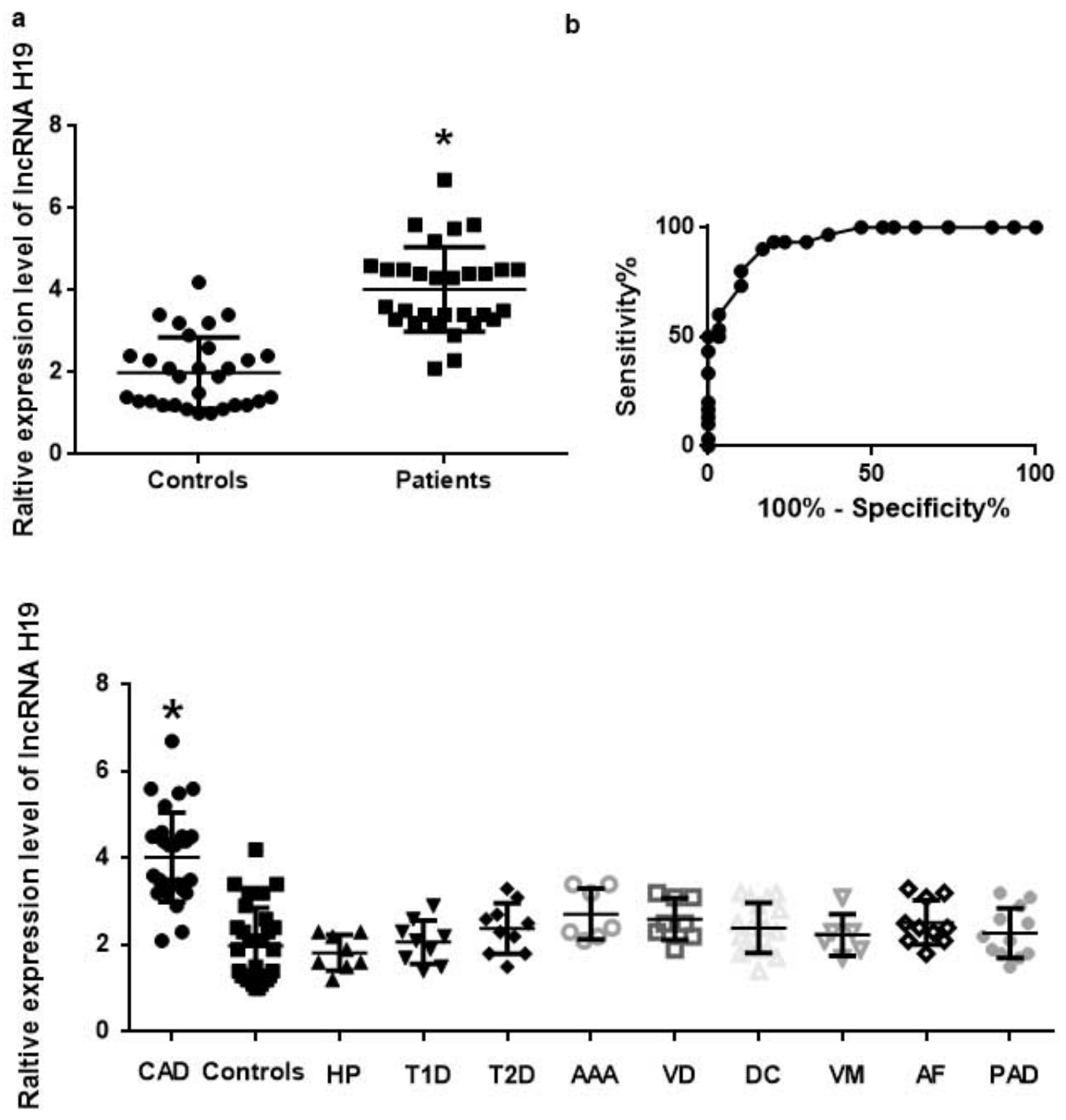

FIGURE 1 LNCRNA H19 EXPRESSION IN PATIENTS WITH CAD AND THE DIAGNOSTIC VALUE.

A Relative expression of IncRNA H19 in 30 patients with CAD; B R Diagnostic value of IncRNA GAS5 for CAD analyzed using ROC curve analysis; (Notes: * compared with the control group, $p<0.05$.)

C Differential expression of IncRNA H19 in patients with different types of cardiovascular diseases (Notes: ${ }^{*}$ compared with the control group or patients with other types of disease; HP, hypertension, T1D, type 1 diabetes; T2D, type 2 diabetes; AAA, abnormal aortic aneurysm; VD, valvular disease; DC dilated cardiomyopathy; VM, viral myocarditis; AF, atrial fibrillation; PAD peripheral artery disease.)

in patients with acute coronary syndrome and stable angina pectoris, which were two subtypes of CAD, indicating that low serum omentin-1 level may serve as an indicator for CAD. In another study, an increased serum level of visfatin and decreased serum level of vaspin were detected in asymptomatic patients with CAD, and the reduced serum levels of vaspin were found to be correlated with the severity of CAD.
LncRNAs have been proved to be involved in almost every aspect of all key biological and pathological processes in the human body ${ }^{10}$. Previous studies have shown that the development of certain human diseases is usually accompanied by changes of some lncRNAs in serum. Therefore, the application of serum lncRNAs in the diagnosis of human diseases has become increasingly popular. However, the application of lncRNAs as a biomarker in the 

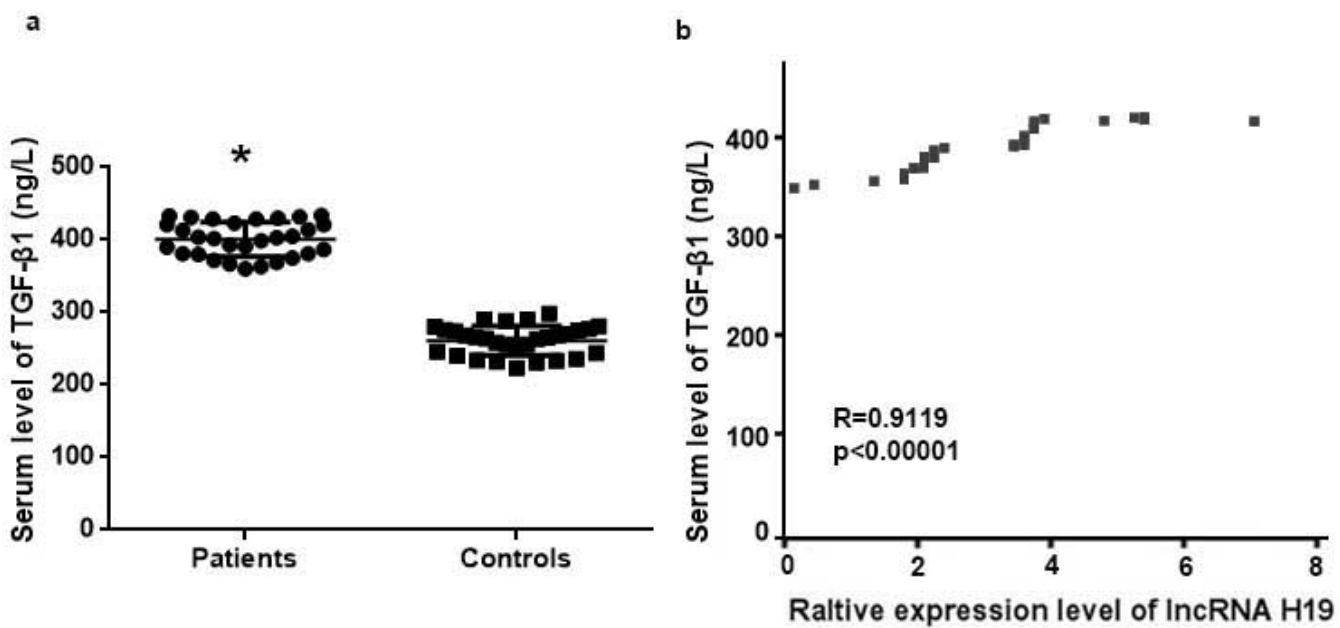

FIGURE 2 CORRELATION BETWEEN THE SERUM EXPRESSION LEVEL OF H19 AND THE SERUM LEVEL OF TGF- $\beta 1$ a Serum level of TGF- $\beta 1$ in CAD patients and healthy control individuals. b Correlation between the serum expression level of $\mathrm{H} 19$ and the serum level of TGF- $\beta 1$ lanalyzed using the Pearson correlation analysis.

Notes: "compared with the control group, $p<0.05$

a

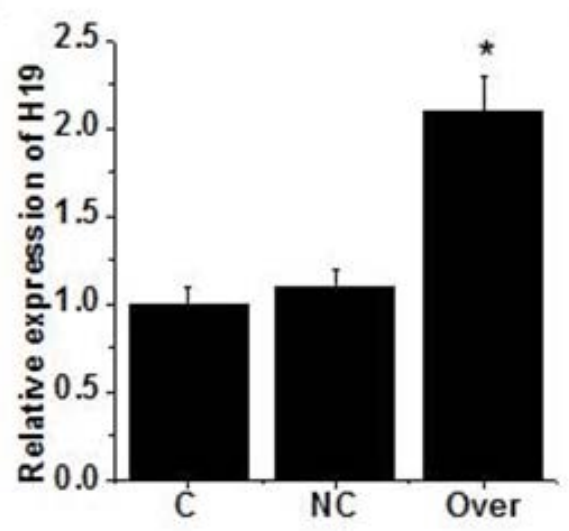

b

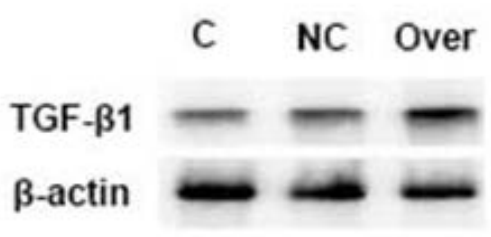

b
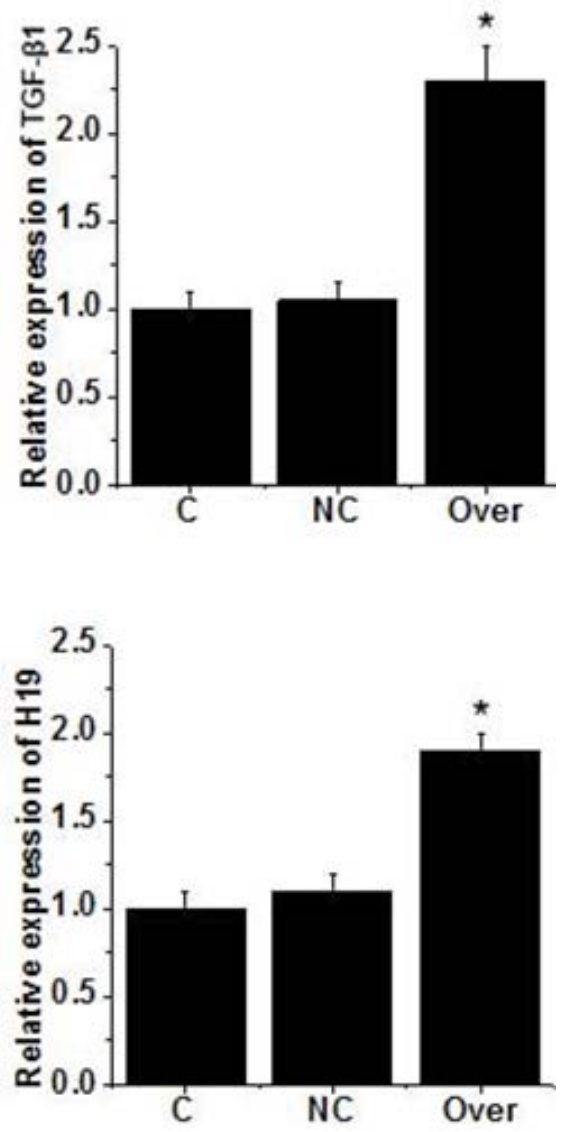

FIGURE 3 H19 OVEREXPRESSION INCREASED THE EXPRESSION LEVEL OF TGF- $\beta 1$ IN HCAECS

a Expression of H19 in HCAECs with different treatments; b Expression of TGF- $\beta 1$ mRNA in HCAECs with different treatments; c Expression of TGF- $\beta 1$ protein in HCAECs with different treatments.

Notes: ${ }^{*}$ compared with the control group or negative control group, $\mathrm{p}<0.05$. 
diagnosis of CAD has not been well studied, except for one recent study which found that plasma lncRNA CoroMarker was significantly increased in the plasma of CAD patients but not in patients with other types of cardiovascular diseases, and the decreased expression level of this IncRNA could be used to predict CAD accurately. The functionality of IncRNA H19 is extensive in different disease models. Especially in cancer, IncRNA H19 is an oncogene that is usually overexpressed, and circulating IncRNA H19 in blood has been proved to be a biomarker for different types of cancers such as breast cancer and gastric cancer. In a recent study, Zhang et al. reported that the serum level of IncRNA H19 was significantly increased in the plasma of patients with CAD, and the increased expression level of IncRNA H19 was significantly correlated with the increased risk of CAD in the Chinese population. Consistent with previous studies, in our study, the serum level of H19 was specifically increased in patients with CAD but not in healthy individuals or patients with other types of cardiovascular diseases. Besides that, the ROC curve analysis also showed that serum H19 could also be used to accurately predict CAD, indicating that serum H19 is a specific and accurate diagnostic marker for CAD. Stability is critical for biomarkers. It is known that the expression of some lncRNAs can be induced or regulated by patients' living habits, such as smoking and drinking. In our study, age, gender, and patients living habits showed no significant effects on H19 expression, while the H19 expression level was increased with the prolonged course of the disease.
These data suggest that serum H19 is a promising biomarker for CAD.

Although $\mathrm{H} 19$ has been proved to correlate with CAD, its mechanism is still unclear.

It is well known that $\mathrm{H} 19$ can interact with TGF- $\beta 1$, and polymorphism and the expression of TGF- $\beta 1$ are related to the development of CAD. In our study, the serum level of H19 was found to be positively correlated with the serum level of TGF- $\beta 1$. Besides that, H19 overexpression also significantly increased the expression level of TGF- $\beta 1$ in HCAEC. These data suggest that the upregulation of H19 expression may play a role in CAD by increasing the expression level of TGF- $\beta 1$.

\section{CONCLUSION}

In conclusion, the serum level of H19 was higher in patients with CAD than in healthy individuals or patients with other types of cardiovascular diseases. Serum H19 is a stable, specific and accurate diagnostic marker for CAD. The serum H19 expression level was positively correlated with the plasma level of TGF- $\beta 1$, and H19 overexpression significantly increased the TGF- $\beta 1$ protein level in HCAEC. Our study is still limited by the small sample size. Future studies with more significant sample sizes may be needed to confirm our conclusions further.

\section{Acknowledgments}

This study was supported by the Natural Science Foundation of Hubei Province (No. 2014CFB209)

\section{RESUMO}

OBJETIVo Nosso estudo teve como objetivo investigar o valor diagnóstico do IncRNA H19 para doença arterial coronariana (DAC) e explorar os possíveis mecanismos. Métodos Um total de 30 pacientes com DAC e 30 pessoas saudáveis, bem como pacientes com diferentes doenças cardiovasculares foram incluídos neste estudo. O sangue foi extraído de cada participante para preparar amostras de soro e a expressão de IncRNA H19 foi detectada por qRT-PCR. A análise da curva ROC foi utilizada para analisar o valor diagnóstico de H19 para DAC. Efeitos da informação básica dos pacientes e estilo de vida na expressão de H19 foram analisados. O nível plasmático de TGF- $\beta 1$ foi medido por ELISA. A linha de células endoteliais da artéria coronária primária (HCAEC) humana de sobre-expressão de H19 foi construída e os efeitos da sobre-expressão de H19 na expressão de TGF- $\beta 1$ foram analisados por Western blot. Resultados A expressão de H19 foi especificamente regulada positivamente em pacientes com DAC, mas não em pessoas saudáveis e em pacientes com outros tipos de doenças cardiovasculares. A análise da curva ROC mostrou que o nível de expressão de H19 pode ser usado para prever com precisão a DAC. Sexo, idade e estilo de vida dos pacientes não têm efeitos significativos sobre a expressão de H19, mas a expressão de H19 foi maior em pacientes com curso mais longo da doença em comparação com os controles. A expressão de H19 correlacionou-se positivamente com o nível sérico de TGF- $\beta 1$ e a superexpressão de H19 aumentou significativamente o nível de proteína de TGF- $\beta 1$ em HCAEC. Conclusão A superexpressão de H19 participa da patogênese da DAC aumentando o nível de expressão de TGF-ß1 e o nível de expressão de H19 pode servir como marcador diagnóstico de DAC.

PALAVRAS-CHAVE: Doença da artéria coronariana. Diagnóstico. RNA Longo não Codificante. Fator de Crescimento Transformador beta1. 


\section{REFERENCES}

1. Hanson MA, Fareed MT, Argenio SL, Agunwamba AO, Hanson TR. Coronary artery disease. Prim Care. 2013;40(1):1-16.

2. Teramoto T, Sasaki J, Ishibashi S, Birou S, Daida H, Dohi S, et al. Coronary artery disease. Executive summary of the Japan Atherosclerosis Society (JAS) guidelines for the diagnosis and prevention of atherosclerotic cardiovascular diseases in Japan - 2012 version. J Atheroscler Thromb. 2014;21(2):86-92.

3. Gao R, Yang $Y$, Han $Y$, Huo $Y$, Chen I, Yu B, et al. Bioresorbable vascular scaffolds versus metallic stents in patients with coronary artery disease: ABSORB China Trial. J Am Coll Cardiol. 2015;66(21):2298-309.

4. Mohr FW, Morice MC, Kappetein AP, Feldman TE, Ståhle E, Colombo A, et al. Coronary artery bypass graft surgery versus percutaneous coronary intervention in patients with three-vessel disease and left main coronary disease: 5-year follow-up of the randomised, clinical SYNTAX trial. Lancet. 2013;381(9867):629-38.

5. Mäkikallio T, Holm NR, Lindsay M, Spence MS, Erglis A, Menown IB, et al; NOBLE study investigators. Percutaneous coronary angioplasty versus coronary artery bypass grafting in treatment of unprotected left main stenosis (NOBLE): a prospective, randomised, open-label, non-inferiority trial. Lancet. 2016;388(10061):2743-52.

6. Mann D, Zipes D, Libby P, Bonow R. Braunwald's heart disease: a textbook of cardiovascular medicine. 10 ${ }^{\text {th }}$ ed. Philadelphia: Saunders; 2014.

7. He QY, Lau GK, Zhou Y, Yuen ST, Lin MC, Kung HF, et al. Serum biomarkers of hepatitis B virus infected liver inflammation: a proteomic study. Proteomics. 2003;3(5):666-74.

8. Higashimoto Y, Iwata T, Okada M, Satoh H, Fukuda K, Tohda Y. Serum biomarkers as predictors of lung function decline in chronic obstructive pulmonary disease. Respir Med. 2009;103(8):1231-8.

9. Perkel JM. Visiting "noncodarnia". Biotechniques . 2013;54(6):301, 303-4.

10. Esteller M. Non-coding RNAs in human disease. Nat Rev Genet. 2011;12(12):861-74. 